\title{
UMA CAMPANHA POR DIREITOS IGUAIS: A DIÁSPORA INDIANA E A CIDADANIA GANADENSE
}

James W. St.G. Walker'

Resumo: Este artigo trata das campanhas políticas em torno do acesso aos direitos políticos no Canadá, empreendida por imigrantes dos domínios coloniais britânicos da India (em especial o Punjabi, na Índia), no contexto da Segunda Guerra Mundial e no imediato pós-guerra. O objetivo do texto é mostrar os argumentos e estratégias utilizados pelos atores políticos - sobretudo os próprios imigrantes -, que mobilizaram os discursos dos direitos políticos e dos direitos humanos para sensibilizar a opinião pública, conseguir seu apoio e reconfigurar a noção de “cidadania” no Canadá do pós-guerra.

Palavras-Chave: Direitos Humanos; Império Britânico; Indianos; Canadá; Século XX

Abstract: This article deals with the political campaigns over access to political rights in Canada, undertaken by immigrants from the British colonial rule of India (especially Punjab, India) in the context of World War II and the immediate postwar period. The purpose of the paper is to show the arguments and strategies used by political actors - especially the immigrants themselves - who mobilized the discourse of political rights and human rights to raise awareness, get their support and reconfigure the notion of “citizenship” in post-war's Canada.

Key-Words: Human Rights; Indians; British Empire; Canada; XXth Century

\section{INTRODUÇÃO}

Por vezes é mais fácil duvidar do que acreditar no progresso dos direitos civis e dos direitos humanos ao longo do século XX. Afinal, Ruanda, Kosovo e Guantanamo serviriam como evidências de que o século não terminou muito melhor do que começou. Mas existem outras evidências que indicam alguns objetivos positivos alcançados. O contraste provoca dúvidas sobre por que alguns grupos,

\footnotetext{
' Departamento de História, University of Waterloo (Canadá). Este artigo foi originalmente apresentado no Seminário Internacional "Relações Raciais, Direito e História" na Universidade Federal de Santa Catarina, em 17 de setembro de 2007. Tradução: Henrique Espada Lima e Beatriz Gallotti Mamigonian.
} 
em momentos e locais específicos, conquistaram avanços na luta por igualdade e cidadania plena. A comunidade indiana no Canadá serve como um caso-teste. Eles alcançaram o direito ao voto em 1947, bem no começo do que foi chamado de uma "revolução dos direitos”, acontecida tanto no Canadá quanto globalmente. O sucesso deles foi resultado de forças globais, ou de iniciativas locais e circunstâncias favoráveis? O que a comunidade indiana do Canadá reivindicava era cidadania plena. Como eles superaram suas desvantagens políticas e conquistaram o apoio dos outros canadenses é uma questão histórica interessante cuja resposta pode iluminar nosso entendimento do movimento geral pela igualdade racial e pelos direitos humanos no Canadá. A conquista da cidadania plena, a revogação da legislação de discriminação com base na "raça" foi o primeiro passo no longo caminho da justiça para minorias racializadas. Esse caso pode ter implicações para estratégias contemporâneas, na medida em que esta jornada ainda está em curso.

\section{O CASO}

Em 1907 a legislatura da província canadense da Colúmbia Britânica votou unanimemente para excluir "Hindus", como eram conhecidas oficialmente as pessoas de origem indiana, do direito ao voto no nível provincial. Os chineses e japoneses já haviam perdido o direito ao voto na Colúmbia Britânica, e a exclusão deles, explicitamente com base na "raça", foi considerada constitucional pelo Privy Council $2^{2}$ em 1903. Ao mesmo tempo, foram tomadas medidas para desencorajar a vinda de asiáticos para a província. A imigração chinesa foi restringida pela cobrança de um infame imposto individual a partir de 1885 e, depois dos conflitos anti-asiáticos de Vancouver em 1907, um "acordo de cavalheiros" foi feito com o Japão de modo a restringir a imigração a partir de lá. A Índia era mais complicada, porque fazia parte de um Império ao qual também pertencia ao Canadá. A solução foi formular mecanismos eufemísticos que excluiriam indianos mantendo a aparência de neutralidade. O mais efetivo foi uma ordem que permitia às autoridades rejeitar todos os imigrantes que chegassem ao país, mas cujas viagens não tivessem sido diretas. Isto resultava em exclusão, pois em 1908 não havia meios para fazer uma viagem direta entre a Índia e o Canadá. ${ }^{3}$

$\mathrm{Na}$ época que essas barreiras de entrada no país e à participação política foram levantadas, a comunidade indiana consistia de aproximadamente 5.000 pessoas, quase todas Sikhs da região do Punjab, na maioria homens jovens entre $20 \mathrm{e}$ 30 anos, muitos casados, que tinham deixado suas famílias na Índia. Eles eram os clássicos "sojourners" (residentes temporários). Com salários dez a quinze vezes maiores do que na Índia, e com intenção firme de voltar ao seu país de origem, eles ainda assim protestaram contra essas medidas discriminatórias. Isso requer alguma explicação. Em primeiro lugar, o fato de não serem registrados como eleitores 
os desqualificava para muitos empregos, contratos e licenças na província, assim como para obrigações civis tais como a participação em júri e participação como eleitor no âmbito federal. Entretanto, ainda mais que estas incapacidades práticas, a falta de registro eleitoral era produndamente simbólica, refletindo o fato de que as pessoas vindas da Índia (assim como da China e do Japão) e seus descendentes nascidos no Canadá não pertenciam à nação e não participavam da democracia canadense. Eles eram marcados como outsiders permanentes. ${ }^{4}$

Foi portanto por princípio que os Sikhs residentes no Canadá lançaram sua campanha por direitos iguais, que durou quatro décadas. A questão fundamental era o reconhecimento como iguais, o que implicava na revogação de leis que os excluíam da vida cívica e deixava suas famílias e amigos fora do Canadá. Mas o princípio baseava-se em elementos práticos, à medida que alguns dos primeiros migrantes resolveram que gostariam de permanecer no Canadá. Os que eram mais insatisfeitos voltaram para a Índia ou se mudaram para outros lugares. Os que ficaram criaram um nicho econômico, trabalhando na dinâmica indústria madeireira, compraram casas e, sob essas novas circunstâncias, alguns quiseram trazer suas mulheres e crianças.

\section{APELANDO PELA JUSTIÇA}

A evidência de que eles se tornavam mais do que residentes temporários foi a inauguração de um templo Sikh, ou gurdwara, que abriu suas portas em 1908, e da Sociedade Khalsa Diwan (KDS, no original), que cuidava do templo e dos negócios da comunidade. Filiais da KDS surgiram em todas as cidades da província onde havia uma população de Sikhs. A KDS e o gurdwara deram base para a campanha que veio depois, levantando fundos, facilitando a comunicação e os encontros públicos, tudo sob a santidade da religião.

A tática original adotada na campanha por igualdade era de apelar para as autoridades usando petições e delegações pessoais. É interessante que tenham direcionado suas demandas inicialmente ao que chamavam de "o Governo Doméstico" ("the Home Government”) em Londres, com petições em 1910 e 1911. Só quando foram ignorados é que se voltaram para o governo canadense em Ottawa. Ainda que tenham sido recebidos com educação pelo gabinete federal, as mudanças não ocorreram; assim, uma nova delegação foi a Londres e à Índia em 1913 para levar o caso ao Vice-Rei e a uma série de reuniões encontros pela Índia afora. A lógica da estratégia imperial era que eles baseavam a demanda por igualdade no "direito de nascimento como súditos britânicos". Suas petições baseavam-se na lealdade dos Sikhs ao Império, merecendo tratamento justo por parte dos britânicos. Eles também enfatizaram que, ao contrário dos chineses e japoneses "mongólicos”, os povos do norte da Índia eram "arianos” como os britânicos e canadenses 
e, como iguais na raça, não deviam ser tratados como inferiores. Eles argumentavam que os chineses podiam entrar no Canadá desde que pagassem o imposto individual, os japoneses tinham seu acordo de cavalheiros; apenas os indianos, que eram ao mesmo tempo arianos e súditos britânicos, eram excluídos, e isso era por eles considerado "humilhante" e "um estigma". "Mesmo o negro" e "a ralé da Europa” tinham mais direitos do que eles na Colúmbia Britânica. Eles argumentavam que a separação das famílias era imoral e uma violação dos seus "direitos humanos naturais”, que a cláusula da viagem contínua fazia do sistema de justiça britânico uma piada porque era uma lei que não podia ser obedecida e que contribuintes e cidadãos honestos mereciam o voto. ${ }^{5}$

\section{TESTANDO A LEI}

Não demorou muito para que a comunidade percebesse que os apelos por justiça ficavam sem resposta e assim algumas pessoas, com apoio financeiro da KDS, decidiram levar seus casos aos tribunais. Vários homens indianos voltaram à Índia para buscar suas famílias e tentar entrar no Canadá. Quando aterrissaram em Vancouver em 1912, os maridos foram admitidos como residentes que retornavam, mas as mulheres e crianças foram detidas para serem deportadas. Manifestações e uma campanha de envio de cartas atraiu o interesse do público para a questão, particularmente na costa leste canadense, onde o jornal Montreal Witness proclamou que "o domicílio da mulher é o de seu marido. Uma lei que pretende atacar esse princípio ataca as bases da sociedade”. As famílias foram libertadas por habeas corpus, mas as ordens de deportação ainda vigoravam quando, em maio de 1912, o governo decidiu deixá-los ficar. Não como um direito, mas como um ato de misericórdia. Os regulamentos não mudaram. Ao mesmo tempo um desafio aberto à lei eleitoral foi iniciado por Hossain Rahim, que tinha sido cadastrado como eleitor e depois tentou votar. Ele foi preso e acusado de violar a lei de 1907 que vetava a participação eleitoral de alguns grupos. Mais uma vez, a comunidade levantou fundos para defender Rahim nos tribunais como uma forma de testar a lei e mais uma vez o resultado foi inconclusivo. $\mathrm{O}$ júri não chegou a concordar em um veredito e assim o indiciamento permaneceu, e Rahim foi liberado "sob promessa de retornar se a Coroa resolvesse voltar ao caso". ${ }^{6}$

Uma vitória genuína, ainda que temporária, sobre a lei de imigração foi alcançada em 1913 quando um juiz decidiu que a formulação do regulamento de imigração não coincidia com os termos da Lei de Imigração. O governo rapidamente eliminou as ambiguidades e omissões da lei, mas enquanto isso Gurdit Singh fretou um navio japonês, o Komagata Maru, e recrutou 376 pessoas, a maioria Sikhs, para ir para o Canadá. Eles chegaram em Vancouver em maio de 1914 e foram retidos a bordo do navio enquanto a KDS defendia seus apelos 
legais na justiça. No fim, esse caso também foi perdido e depois disso a tática de usar os tribunais para mudar a lei foi abandonada. ${ }^{7}$

\section{FORJANDO ALIANÇAS}

Como uma comunidade pequena e isolada de apenas 1.016 pessoas pelo recenseamento de 1921, os Sikhs da Colúmbia Britânica reconheceram que seria necessário apoio externo para mudar as leis. Desde que os casos de família angariaram uma simpatia considerável do conjunto dos canadenses, a questão da unificação das famílias aparecia como uma causa que atrairia aliados. Dr. Sundar Singh, um dos delegados enviados a Ottawa em novembro de 1911 ficou na região leste do Canadá, dando palestras para grupos de igrejas e em filiais do Canadian Club e do Empire Club. Atingir esses públicos era uma estratégia calculada, pois eram receptivas aos argumentos por unidade imperial e pela santidade da família. Em Toronto um “Comitê Canadá Índia” foi formado sob a inspiração de Singh, presidido por Sir Robert Falconer, reitor da Universidade de Toronto. O Comitê enviou cartas para Ottawa; e mesmo delegações compostas por cidadãos proeminentes de Toronto realizaram encontros públicos e alimentaram a imprensa e financiaram uma série de panfletos, todos convocando os canadenses a protestarem contra a legislação que mantinha separadas famílias britânicas de origem indiana, leais ao Império. Resoluções foram adotadas pelos encontros anuais das igrejas Metodista e Presbiteriana, pela Sociedade dos Amigos, a WCTU e outras organizações que insistiam que a caridade cristã e a dignidade humana demandavam a admissão dos membros da família. ${ }^{8}$

A comunidade também publicou jornais com edições em inglês e punjabi, com financiamento da KDS. Os exemplares em inglês eram voltados para a população canadense em geral, enquanto os impressos em punjabi foram enviados para a Índia para informar as pessoas de lá sobre os problemas enfrentados por seus semelhantes no Canadá, e exercendo pressão sobre o governo da Índia para que apoiasse a campanha. Essas atividades receberam apoio de organizações como o Congresso Nacional Indiano em 1914 e 1915; em 1915 a resolução de apoio foi proposta por Mohandas K. Gandhi. O governo da Índia também respondeu positivamente. Nas "Imperial War Conferences" (Conferências Imperiais sobre a Guerra) em Londres em 1917 e 1918, representantes indianos propuseram resoluções que permitiriam a indianos residentes nos Domínios britânicos trazer suas famílias da Índia. Em 1918 o primeiro ministro Borden votou a favor da resolução em defesa da família, e com a pressão contínua da Índia, o governo de Borden aprovou uma medida em 1919 suspendendo a obrigação de viagem contínua e outras restrições para mulheres e crianças de indianos residentes no Canadá. ${ }^{9}$ 
Uma fórmula de sucesso parece ter sido desenvolvida. Assim, os líderes da comunidade a adotaram para fazer campanha por outra questão, a participação eleitoral. Seus jornais começaram a enfatizar que não compartilhavam desse direito à cidadania "enquanto qualquer vadio e tipo inferior da Europa" podia votar. O governo da Índia continuou a pressionar por reforma nas conferências imperiais dos anos 1920 e 1930. A conferência de 1921 aprovou uma resolução que declarava "é desejável que os direitos dos... indianos [vivendo nos domínios] à cidadania seja reconhecido". O primeiro-ministro Arthur Meighen votou a favor, parecendo assim aceitar a extensão do direito ao voto à comunidade diaspórica residente no Canadá. No ano seguinte um funcionário do governo indiano visitou o Canadá para ver como a resolução estava sendo implementada. Mackenzie King, que havia substituído Meighen como primeiro-ministro nesse meio tempo, explicou que Meighen tinha apenas expressado apoio a um princípio, não prometendo ação. E, como era um direito das províncias determinar a participação eleitoral, a decisão era da Colúmbia Britânica, a única província em que eles não tinham direito a voto. Quando lhe foi pedido que fizesse emendas ao direito eleitoral federal diretamente, King prometeu fazê-lo "no momento mais oportuno". ${ }^{10}$

Obviamente, a comunidade indiana precisava de aliados políticos. Quando Mackenzie King se preparava para participar de outra conferência imperial em 1923, o deputado por Montreal, S. W. Jacobs, perguntou-o o motivo pelo qual a resolução de 1921 não havia levado à cidadania plena dos indianos no Canadá. Os deputados pela Colúmbia Britânica reagiram demonstrando que nunca apoiariam tal medida. Apoiado em uma maioria de apenas um voto no parlamento, King só pôde dizer que a questão seria discutida quando a lei eleitoral fosse discutida. Jacobs recebeu o apoio nesse debate do deputado por Winnipeg, James S. Woodsworth, que depois se tornou líder da Federação Cooperativa do Commonwealth. Desde a sua fundação, a CCF se dedicou a defender os direitos eleitorais não apenas de indianos, mas de todos os asiáticos residentes no Canadá e propôs, repetidamente, resoluções tanto na assembléia provincial da Colúmbia Britânica em Victoria quanto na Câmara federal em Ottawa para esse efeito. Mas, como um partido de minoria, eles não podiam pôr seus princípios em prática. Quando a lei eleitoral federal foi debatida em 1934 e 1936, não houve apoio suficiente para a participação eleitoral dos residentes asiáticos. ${ }^{11}$

\section{O IMPACTO DA SEGUNDA GUERRA MUNDIAL}

Quando a crise europeia explodiu em outra guerra mundial, o governo canadense decidiu não recrutar os japoneses e chineses para o serviço militar obrigatório. Os homens indianos não foram levados em consideração naquele momento. E, assim, apenas alguns foram chamados para os exames médicos preliminares ao alista- 
mento. Uma manifestação da KDS em Vancouver votou uma resolução protestando o serviço militar obrigatório e pedindo "os direitos de cidadania legítimos há muito requeridos". Uma petição foi enviada a Ottawa, declarando que se ganhassem direitos eleitorais eles "dariam com prazer sua contribuição ao esforço de guerra”, mas sem eles "protestariam respeitosamente" o serviço compulsório. Em Ottawa acreditava-se que os Sikhs seriam "uma dor de cabeça para o Exército", com requisições de comida e códigos de vestimenta especiais. O governo da Colúmbia Britânica também temia que, se os asiáticos fossem recrutados, a participação eleitoral seria naturalmente o próximo passo. Instruções secretas foram enviadas para os postos de recrutamento do exército: os indianos seriam chamados para o exame médico, mas depois rejeitados como incapazes para o serviço militar. Como essa orientação não foi tornada pública, os jovens tiveram a percepção de que estavam sendo recrutados. Apesar de memorandos internos do governo insistirem que indianos não fossem recrutados, na prática alguns foram e, de qualquer forma, a comunidade guardou a percepção de que o recrutamento estava em curso. ${ }^{12}$

A questão do recrutamento serviu como um imã para o apoio do público à causa. Encontros públicos nos gurdwara, assim como nos teatros de Vancouver e em outras cidades, reuniram um público que não se restringia à comunidade Sikh. Um dos organizadores lembra que esses encontros "pregavam aos convertidos", mas que "os objetivos reais eram aparecer nos jornais e criar publicidade de modo a atingir os não-convertidos”. E funcionou, pois a imprensa da Colúmbia Britânica passou a se preocupar com a disjunção entre direitos e deveres dos cidadãos, com manchetes como "Eles lutam pelo Canadá, querem o voto". Muitos habitantes da província descobriram assim que os "hindus" não tinham direito ao voto, e acabaram se juntando ao movimento de protesto. $\mathrm{O}$ fato que muitos indianos que serviam ao exército voluntariamente tenham comparecido de uniforme nessas manifestações deu ainda mais pungência à mensagem. $\mathrm{O}$ interesse pela causa cresceu muito quando uma delegação visitou o gabinete do governo provincial em Vitória em março de 1943 reivindicando a participação eleitoral e assim, praticamente pela primeira vez, abordando a instituição responsável por sua incapacidade política. Durante essa campanha em momento de guerra, a retórica mudou significativamente. Não se falava em justiça britânica ou em direitos imperiais como súditos britânicos, mas de direitos como cidadãos canadenses. ${ }^{13}$

Em março de 1944 o CCF ${ }^{14}$ propôs um projeto de lei para dar o voto aos "hindus" na Colúmbia Britânica. No curso do debate, George Pearson, secretário provincial e ministro do Trabalho, disse que sua experiência mostrava que hindus "não eram confiáveis, eram desonestos e enganosos", "tinham tendência contrária ao nosso padrão de vida” e não mereciam "direitos plenos de cidadania”. O projeto foi rejeitado na legislatura, só com apoio do CCF, mas o debate e particularmente 
os comentários de Pearson receberam publicidade no âmbito provincial. A KDS organizou uma manifestação de protesto e enviou uma delegação para se encontrar com Pearson e pedir retratação dos seus insultos. É interessante que pela primeira vez eles tenham sido acompanhados por uma delegação de canadenses de origem chinesa que reconheciam uma confluência de interesses na questão da participação eleitoral. Provocada pelas alegações de Pearson, a KDS decidiu confrontar a imagem negativa diretamente. Eles conduziram uma pesquisa em vários centros que tinham população indiana, registrando seus números (1.756), taxa de alfabetização (76,1\%), negócios independentes (257), compra de Bônus de Guerra (446.730 dólares canadenses) e outros indicativos de sua respeitabilidade e valor como cidadãos. A pesquisa foi anexada a uma nova petição enviada ao gabinete provincial em janeiro de 1945. Quando o CCF reintroduziu o projeto em 1945 ele foi novamente derrotado, mas dessa vez três deputados da maioria governamental contrariaram as indicações do gabinete e votaram a favor. ${ }^{15}$

Nesses debates em 1944-45, tanto na imprensa quanto na assembleia, manteve-se o foco nos direitos canadenses em vez dos britânicos, o que amplificava a nova retórica derivada dos eventos internacionais. A Carta do Atlântico foi invocada para demonstrar que os objetivos de guerra dos aliados eram contrários à restrição à participação eleitoral racialmente determinada praticada na Colúmbia Britânica. Em editoriais e em manifestações da KDS, traçavam-se paralelos entre as políticas raciais canadenses e nazistas. Em 1945, o compromisso das Nações Unidas com os direitos humanos e a igualdade racial forneceu munição pesada para apoiar a demanda por participação igualitária na democracia canadense. Quando conduzia audiências em outubro e novembro de 1946, um comitê da legislatura recebeu apelos dirigidos pelos líderes da comunidade indiana e chinesa, da Legião Canadense, de igrejas, grupos defensores de liberdades civis, da Associação das Nações Unidas e de corpos profissionais, desafiando, com base nos direitos humanos, os regulamentos eleitorais. Enquanto isso, o debate nacional sobre a Lei de Cidadania Canadense em 1946 promovia o ideal da cidadania igualitária para todos os canadenses e atraiu o comentário, em editorial, de que continuar negando a plena participação política "sabotaria” a nova lei. O comitê da Colúmbia Britânica recomendou unanimemente que a legislatura concedesse direitos políticos a todos os canadenses de origem chinesa e indiana e isso foi aceito sem divergências pela legislatura no dia 2 de abril de $1947 .{ }^{16}$

\section{IMPLICAÇÕES}

A vitória foi obviamente incompleta em 1947. Os japoneses foram deixados de fora e os chineses só parcialmente incluídos. A discriminação dos imigrantes continuou por mais vinte anos. Mas uma mudança conceitual fundamental 
tinha acontecido quando se reconheceu a prerrogativa do voto como um direito de cidadania. A comunidade indiana insistia nesse ponto há bastante tempo, invocando um direito britânico nos primeiros anos da campanha. O que mudou não foi o objetivo deles - cidadania igualitária - mas a retórica: antes da Segunda Guerra Mundial a igualdade podia ser invocada a partir das noções de "justiça britânica" e de "fair play". Não funcionou, mas essa era a linguagem disponível. À medida que a linguagem de direitos humanos e de cidadania canadense ganhou uso corrente, a comunidade ajustou sua retórica e reconstruiu seu argumento para termos canadenses e não mais imperiais. Ao ganhar o direito à participação eleitoral nesses termos, eles aperfeiçoaram a definição da cidadania canadense.

Ainda que seus objetivos nunca tenham mudado, as táticas que eles usaram para alcançá-los evoluíram com seus argumentos. As tentativas de convencer as pessoas responsáveis pelas decisões através de petições e delegações tiveram efeito mínimo. A tática mais efetiva, aprendida na luta pela unificação das famílias, era atrair a atenção do público. Foi a demonstração de apoio da população mais ampla que forçou o governo a agir, e não os argumentos lógicos sobre a justiça e o império. A mesma tática foi empregada com mais sucesso ainda no contexto da segunda guerra mundial. Seria um erro atribuir o sucesso da campanha à guerra. O debate legislativo de 1945 na Colúmbia Britânica aconteceu depois da liberação de Auschwitz, depois que os horrores do racismo nazista foram revelados, depois de seis anos de uma guerra travada em nome da democracia, e ainda assim os representantes eleitos rejeitaram o projeto. O que a guerra propiciou foi uma oportunidade, especialmente na questão dos problemas no recrutamento, para que se apelasse emocionalmente para os outros canadenses e ganhar novo apoio para a causa de 40 anos.

Antes que o apelo chegasse a eles diretamente, a maioria dos canadenses não tinha conhecimento da extensão da desqualificação racial, bem como da insatisfação que produzia, em sua própria sociedade. Uma vez confrontados com isso como um "problema", muitas pessoas se mostraram dispostas a adotar a solução proferida da cidadania igualitária. O protagonismo foi claramente do grupo discriminado, a comunidade que percebeu sua própria desigualdade e se mostrou determinada a corrigi-la. O exemplo deles mostra que para ganhar, precisavam conseguir aliados, e para atrair aliados tiveram que se engajar na educação do público. Essa talvez tenha sido a lição mais importante da história de sua luta.

\section{NOTAS}

${ }^{2} \mathrm{O}$ "Privy Council" é uma instituição do Império Britânico e do Canadá em particular, que serve como um Conselho consultivo do poder executivo. (Nota do Tradutor). 
${ }^{3}$ Vancouver Province, 27 de Março de 1907; Cunningham v. Tomey Homma, Appeal Cases (Judicial Committee of the Privy Council), 1903, I 5 I; W.L. Mackenzie King, Report of Mr W. L. Mackenzie King on his Mission to England in connection with the Immigration of Asiatics into Canada, London, HM Stationery Office, 1908; PC 27, 8 de Janeiro de 1908. Um "Hindu" era definido na lei eleitoral provincial como "qualquer nativo da Índia cujos pais não sejam Anglo-Saxões". O termo foi mantido nos documentos oficiais até 1947.

${ }^{4}$ British Columbia Archives (BCA), GR- I 195, Legislative Assembly, Miscellaneous Correspondence, 1942-47, Caixa I, pasta I, Petição da Khalsa Diwan Society, 26 de Janeiro de 1945; British North America Act, s. 41 ; The Electoral Franchise Act, Statutes of Canada, 1885, c. 40, s. 9.

${ }^{5}$ As petições e relatos das delegações foram publicados em várias fontes. Ver, por exemplo, Nand Singh Sihra, Balwant Singh and Narain Singh, "Indians in Canada", The Indian Review (Junho de 1913), p. 453-456. Isabella Ross Broad, An Appeal for Fair Play for the Sikhs in Canada, Victoria, 1913; Victoria Society of Friends of the Hindu, A Summary of the Hindu Question, Victoria, 191 I; The Aryan, Agosto de 191। a Novembro de 1912

${ }^{6}$ Nand Singh Sihra et al., "Indians in Canada", 455; The Aryan, 2/5 (Maio de 19/2).

7 Para um relato detalhado, ver Hugh Johnston, Voyage of the Komagata Maru: The Sikh Challenge to Canada's Colour Bar, Vancouver, UBC Press, 1989. Também é de interesse: Continuous Journey, um filme documentário de 2004, realizado por Ali Kazimi.

8 Panfletos incluiam: Broad, Appeal for Fair Play; Anon., The Hindu Case, Toronto, Canada India Committee, 1915, A Hindu-Canadian, India's Appeal to Canada, Toronto, Canada India Committee, 1916. Submissões feitas pela Igreja e outros grupos de apoio estão na Biblioteca e Arquivos Canadenses (Library and Archives Canada -LAC), RG 76, Vol. 536999, Partes 9 e 10.

9 PC64 I, 26 de Março de 1919. The Aryan e o India and Canada estão nos Katar Singh Fonds, LAC, MG 30 E28।. Relatórios das conferências estão em RG 76, Vol. 386, pasta 536999, partes II, I2 e I3. 10 India and Canada, I/I (Junho de 1929); LAC, RG 25, Vol. I703, pasta 490 e Vol. 2959, pasta B-77; RG 76, Vol. 386, pasta 536999, partes 12, 13, I 4 e I 5; R. Gordon Robertson Fonds, MG 3 I E87, Vol. 2, pasta 12; Vancouver City Archives, Henry Herbert Stevens Fonds, Add Mss 69, Vol. I, pasta 5 , Memorando ao Governador do Canadá por Srinivasi Sastri, 22 de Setembro de 1922.

II Por exemplo: House of Commons, Debates, 29 de Junho de 1923, 4638-4666; 22 de Junho de 1934, 4206-4207; 12, 20 e 27 de Fevereiro de 1936, I II-। 52, 373-391, 573-577.

${ }^{12}$ Canada, Parliament, Special Committee on Orientals in British Columbia, Report and Recommendations, Ottawa, 1941; LAC, RG 27, Vol. 130, pasta 60 I.3-4; Vol. 999, pasta 2- I 14-27; Vol. I 486, pasta 2-I53-I; Vol. 1508, pasta 10-1-14; Simon Fraser University Archives, Hari Sharma Indo-Canadian Oral History Collection, entrevistas gravadas com Ranjit Mattu e Ranjit Hall; entrevistas pessoais, Ranjit Hall, Ottawa, Julho de 2007, Jack Uppal, Vancouver, Agosto de 2007.

${ }^{13}$ Ver as entrevistas anteriores. Ver também: Vancouver Province, 30 de Março de 1940, 14 de Janeiro, 13 de Outubro de 1942, 18 de Janeiro de 1943, 2 de Março de 1943; Vancouver News-Herald, 7 de Janeiro de 1943; Vancouver Sun, 18 de Janeiro, 3 e 25 de Março de 1943; Victoria Times, 2 e 3 de Março de 1943; RG 76, Vol. 387, pasta 536999, parte 17.

${ }^{14}$ O CCF (Co-operative Commonwealth Federation) foi um partido político canadense fundado em Calgari (Alberta) em 1932. De feições socialistas, permaneceu ativo até 1961, quando foi substituído pelo New Democratic Party (nota do tradutor).

${ }^{15}$ A Columbia Britânica não publica transcrições dos debates legislativos, mas foi feito um arquivo com recortes de reportagens jornalísticas, que frequentemente traziam esses debates integralmente. Uma cópia desse material microfilmado pode ser encontrado na Biblioteca da UBC. BCA, GR-I|95, Petição do KDS, 26 de Janeiro de 1945.

16 Victoria Times, I/03/I 943; Vancouver Province, 9/03/I 944, 22/0 I/I947, 19/02/I947, 20/03/I 947, 2 / 04/1947 e 7/09/1947; Vancouver Sun, 29/01/1944, II/03/1944, 19/02/1947; Ottawa Citizen, 20/2/ 1945; Vancouver News-Herald, I2/07/1945, 25/0 I/1947, 17/09/1947; LAC, Robertson Fonds, Memorandum, 4/0I/I943, Vol. 2 file I2; RG 76, Vol. 387, file 536999, part 18. Os chineses receberam direitos politicos a nível municipal em 1948, e em 1949 os canadenses de origem japonesa receberam plenos direitos políticos. 